\title{
DA PRAGMÁTICA DA ESPECIALIZAÇÃO FRAGMENTADA À PRAGMÁTICA DA LIOFILIZAÇÃO FLEXIBILIZADA: AS FORMAS DA EDUCAÇÃO NO MODO DE PRODUÇÃO CAPITALISTA ${ }^{1}$
}

\author{
DE LA PRAGMÁTICA DE LA ESPECIALIZACIÓN FRAGMENTADA A LA PRAGMÁTICA \\ DE LA LIOFILIZACIÓN FLEXIBILIZADA: LAS FORMAS DE EDUCACIÓN EN EL \\ MODO DE PRODUCCIÓN CAPITALISTA
}

\author{
FROM THE PRAGMATIC OF THE FRAGMENTED SPECIALIZATION TO THE \\ PRAGMATIC OF THE MORE FLEXIBLE LYOPHILIZATION: THE WAYS OF THE \\ EDUCATION IN THE CAPITALIST MODE OF PRODUCTION
}

\begin{abstract}
Ricardo Antunes ${ }^{2}$
Resumo: Nossa apresentação procura tratar o tema proposto - Modo de produção e educação - esboçando uma primeira sistematização acerca desta problemática sob a forma de três notas. A primeira nota indica alguns elementos para uma compreensão ampla do conceito de modo de produção em Marx. A segunda nota sugere algumas diferenciações presentes nas diferentes formas da alienação e do estranhamento vigentes no século XX e a terceira nota esboça alguns modos distintos da educação para o capital sob o capitalismo, que denominamos como pragmática da especialização, na variante taylorista-fordista e pragmática da liofilização flexibilizada, na era do toyotismo e da acumulação flexível. Conclui com um excerto breve introduzindo algumas pistas para se pensar a educação para além dos constrangimentos do capital.
\end{abstract}

Palavras-chave: Modo de produção; Educação; Alienação; Estranhamento; Taylorismo; Fordismo; Toyotismo.

Resumen: Esta presentación procura tratar el tema propuesto - Modo de producción y educación - esbozando una primera sistematización acerca de esta problemática bajo la forma de tres notas. La primera nota indica algunos elementos para una comprensión amplia del concepto de modo de producción en Marx. La segunda nota sugiere algunas diferenciaciones presentes en las diferentes formas de alienación y de desconocimiento vigentes en el siglo $\mathrm{XX}$; y la tercera nota esboza algunos modos distintos de la educación para el capital bajo el capitalismo, que denominamos pragmática de la especialización, en la variante taylorista-fordista y pragmática de la liofilización flexibilizada, en la era del toyotismo y de la acumulación flexible. Concluye con un fragmento breve introduciendo algunas pistas para se pensar la educación para además de los constreñimientos del capital.

Palabras-clave: Modo de producción; Educación; Alineación; Desconocimiento; Taylorismo; Fordismo; Toyotismo.

\begin{abstract}
Our presentation treats the proposed theme - Mode of production and education - by seeking an initial sistematisation of this problematic in the form of three notes. The first suggests some elements for a broad understanding of Marx's concept of mode of production. The second suggests some differences present in different forms of alienation and estrangement present in the Twentieth century, and the third explores some distinct modes of education for capital under capitalism, which we define as the pragmatism of specialisation, in its taylorist-fordist variant, and the pragmatism of flexible liofilization in the eara of toyotism and flexible accumulation. I have concluded with a brief excerpt introducing some angles for considering education beyond the constraints of capital.
\end{abstract}

Key words: Mode of production; Education; Alienation; Estrangement; Taylorism; Fordism; Toyotism. 
Ao pensar nesse tema proposto, Modo de produção e educação, para esboçar uma primeira sistematização acerca desta problemática, me ocorreu tratá-lo em três notas:

\section{Primeira nota: $O$ modo de produção em Marx.}

O modo de produção para Marx só pode ser compreendido através de uma articulação complexa - em Marx ela é verdadeiramente genial - entre o mundo da objetividade e o mundo da subjetividade. Marx conseguiu fugir de "dois desvios", ou "duas armadilhas": a armadilha de um objetivismo naturalizado, mecanicizado e determinista, e também do subjetivismo que isola, fragmenta, e hiperdimensiona esta esfera em detrimento do mundo complexo das causalidades e determinações.

Mas, no conjunto da obra marxiana a categoria da totalidade é central - ele a retoma de Hegel onde os distintos momentos desta totalidade, o econômico, o político, o ideológico, o valorativo são ao mesmo tempo, simultaneamente, determinantes e determinados. O que tolhe qualquer possibilidade, quando se toma a obra do Marx em seu conjunto, de pensar qualquer forma de determinismo.

Os críticos que atribuem determinismo à obra de Marx desconsideram cabalmente a riqueza e complexidade de sua obra. E se a consideram, e ainda assim vêem nele determinismo, ou são frágeis (esses críticos) ou são, digamos assim, superficiais. É fácil, em uma obra desse porte, pegar uma passagem aqui e ali, fragmentada e isolada de seu contexto maior e atribuir a Marx, por exemplo, não só o determinismo, mas uma conotação, como se faz freqüentemente, de que Marx era teleológico. Só uma cabal desconsideração de sua obra é que pode imaginar que Marx tem um telos (como Hegel, por exemplo), o telos como a finalidade da história. Para dar dois elementos que são constantemente atribuídos a Marx. Freqüente e injustamente.

Portanto, o modo de produção para Marx não se resume estritamente à produção, mas é o modo de produção e de reprodução da vida. É profundamente relacional e é recíproco. As determinantes são determinadas. Isto não elide um problema que é fundamental, que é o da determinação em última instancia. Marx vai dizer: há uma determinação em última instância... Esse "em última instancia" não é nem em primeira instância e nem o sempre. E esse "em última instancia" é para mostrar que política, ideologia, o mundo valorativo, o simbólico, não voam livres pelo ar, não têm autonomia completa em relação ao mundo real. Marx constatou desde seus primeiros estudos de juventude, como sua Crítica da Filosofia do Direito de Hegel, em particular em sua Introdução, que a anatomia da sociedade civil se encontra na economia política. Marx está usando aqui a expressão dos filósofos iluministas até Hegel, a sociedade civil no sentido da sociedade burguesa e de classe. A sua determinação, em última instância, está no mundo material. Mas atenção! - não é no mundo restrito da economia. E não é também no mundo restrito da política. É o universo da economia política. Essa é a ciência nova de que Marx foi o maior construtor. Porque a economia política é a negação da economia isolada como dominante ou da política também isolada como prevalente. Porque elas são inter-relacionais. São determinantes e são determinadas. Não é difícil ver na história tantos momentos em que a política se sobrepõe determinando a economia e vice-versa. 
Portanto, o conceito do modo de produção em Marx só pode ser pensado como um conceito na sua totalidade. Com isso, Marx rompe com as leituras que seccionam o mundo da objetividade e o mundo da subjetividade e a sua dimensão inter-relacional. A sua reciprocidade verdadeiramente dialética faz com que a construção marxiana seja, neste sentido, absolutamente fundamental, enquanto tentativa de compreender a totalidade da vida social, a busca do máximo de conhecimento possivel que a ciência pode fazer do modo de produção do ser e da vida, num dado momento da história.

Por isso é tão verdade que a consciência é determinada pelo ser, quanto que o ser também é determinado pela consciência. Lembra? "O educador também tem que ser educado...” É assim que entendo a noção de modo de produção no Marx, profundamente inter-relacional, dialética, caracterizada pelas determinações reciprocas. Essa é a primeira nota, que me leva à segunda nota.

\section{Segunda nota: As formas diferenciadas da alienação/estranhamento no século XX.}

Uma contribuição decisiva de Marx é a constatação de que o trabalho, no capitalismo acaba assumindo a forma de trabalho alienado ou estranhado. Vou deixar aqui o debate entre as similitudes e diferenças entre Entäusserung e $o$ Entfremdung em Marx, freqüentemente (e erroneamente) traduzidos como sinônimos e remeto os leitores aos meus textos onde trato do problema. Erro que cometeram grande parte das traduções francesas, inglesas, com algumas exceções importantes em língua italiana e também no espanhol. Felizmente para nós, as traduções mais recentes têm procurado tratar dessa disjuntiva e dessa polêmica de modo mais preciso. O trabalho é estranhado para Marx - na medida em que o estranhamento expressa a dimensão de negatividade sempre presente do processo de produção capitalista, onde o produto do trabalho não pertence ao seu criador. Esse é, para Marx, a primeira expressão do estranhamento.

Segundo momento (uma vez que são quatro os momentos constitutivos do processo de estranhamento -ou alienação - em Marx): o trabalho que não se reconhece no produto do seu trabalho, e que dele não se apropria, é um trabalho que não se reconhece no próprio processo laborativo em que ele se realiza. Ele não se realiza, mas ele se estranha, se fetichiza no próprio processo de trabalho.

Isso leva ao terceiro momento, o indivíduo, o ser que trabalha, não se reconhece enquanto uma individualidade nesse ato produtivo central da sua vida, e isto leva à quarta dimensão ou quarto momento da alienação/estranhamento do trabalho: quem não se reconhece como indivíduo, não se vê como parte constitutiva do gênero humano. Essa, digamos de modo muito sintético, é a formulação presente nos Manuscritos Econômico-Filosóficos de 1844. Não posso, aqui, me alongar neste desenho introdutório, para não comprometer as partes seguintes de minha exposição.

E n'O Capital, nas várias partes onde Marx trata do fetichismo da mercadoria e do problema da reificação ou da coisificação, na sua concretude no mundo fabril, o problema do estranhamento ganha ainda muito mais densidade do que na obra de 1844, que é uma primeira incursão sobre a temática. Os Manuscritos Econômico-Filosóficos são a primeira incursão do Marx na economia política, ainda muito 
preliminar e bastante filosófico. O Marx era um filósofo que estava rompendo com a tradição filosófica alemã da qual era herdeiro, o hegelianismo de esquerda.

É este o verdadeiro momento de ruptura no Marx e não outro. Ele faz essa ruptura, essa crítica ontológica, quando salta do idealismo hegeliano para o materialismo histórico e para construção de seu projeto dialético. O que se efetiva quando ele elabora a Crítica da Filosofia do Direito de Hegel - em fins de 43 e começo de 44 - e escreve um texto magistral chamado a Introdução, que já mencionei anteriormente.

Desde o final de 1843 e começos de 1844, Marx começa a empreender a sua formulação com os adensamentos ontológicos materialistas que ele desenvolver ao longo de sua obra. Porque este - a Introdução - é um texto de nascimento e não de consolidação da sua nova concepção. Nele, por exemplo, não há ainda a teoria da mais valia... Nesse texto de 1843/44, não havia sequer a sua teoria da alienação, que aparecerá nos Manuscritos de 1844, mas só uma preliminar menção dela, bem como tudo o que veio depois na construção marxiana, freqüentemente com apoio decisivo do Engels. Se a estatura de ambos é desigual, isso não é um demérito ao Engels, mas isso é um reconhecimento do caráter magistral da obra do Marx. A contribuição engelsiana foi, entretanto, decisiva. Bastaria citar aqui dois textos que tiveram um papel central: o Esboço da Crítica da Economia Política, texto que Marx lê muito cedo, quando ainda não tinha apreendido a dimensão fundante da economia política, mas estava começando, pela sua atividade jornalística, a tratar da questão ao refletir sobre o roubo da lenha; a questão da greve dos operários da Silésia; à questão da habitação, etc, temas que remetiam à esfera da economia política.

E o texto A Situação da Classe Trabalhadora na Inglaterra - recentemente republicado em nossa coleção Mundo do Trabalho (Boitempo), numa edição sob os cuidados de José Paulo Netto. Esse livro mostrou concretamente quem era o proletariado que Marx ainda tratava num plano filosófico e abstrato (como na Introducão de 1844).

Muito bem, se assim era na sociedade do século XIX, no século XX ela não só manteve as alienações típicas do século XIX, mas elas se intensificaram e complexificaram. Isso porque o capitalismo não é um sistema paralisado e linear. E o século XX foi marcado por um duplo processo de alienação/estranhamento; ainda que mantenha essencialmente os seus traços ontológicos fundamentais, há novas particularidades e singularidades na forma de ser da alienação contemporânea.

Quais foram os dois modos de ser dessa alienação/estranhamento no século XX, em Iniciemos pelo binômio taylorismo/fordismo, forma pela qual o capitalismo se desenvolveu ao longo de todo século XX. Quem lê com cuidado os capítulos d'O Capital, quando Marx se refere à transição da manufatura para grande indústria, vai ver que o taylorismo e o fordismo têm muito mais elementos de continuidade do que de descontinuidade em relação à grande indústria do século XIX. Vivenciávamos um processo, para usar uma expressão do Lukács, de "desantropomorfização do trabalho", que é muito acentuado desde os inícios da Revolução Industrial, nos séculos XVIII e XIX e depois ao longo do século XX.

O que tipificaria a alienação ou o estranhamento do trabalho na sociedade capitalista do século XX moldada pela indústria tayloriano/fordista? Tempos Modernos, de Chaplin, é a expressão no plano fílmico mais genial! Mas eu poderia lembrar dois grandes autores que deram fotografias muito felizes dessa processualidade. O primeiro deles é o Lukács, num livro marcante, publicado em 1923, onde há um 
capítulo chamado $A$ Coisificação e a Consciência do Proletariado, que antecipa teses que estavam nos então desconhecidos Manuscritos Econômico-Filosóficos, de Marx de 1844, livro que só foi publicado em 1932. Aliás, vale lembrar, os Manuscritos de 1844 foram publicados com a participação do Lukács, que estava na União Soviética, exilado, no início dos anos 1930 e fora chamado por Riazanov para participar desse processo de organização das obras originais do Marx.

E o outro grande autor que percebeu isto com uma astúcia excepcional os modos de ser do trabalho taylorista/fordista e suas repercussões na subjetividade do trabalho foi Antônio Gramsci. No ensaio Americanismo e fordismo vai mostrar que o taylorismo e o fordismo, ou o "americanismo" como denominava Gramsci, criava uma concepção do homem integral para o capital.

Fundamentalmente o trabalho tayloriano-fordista, embora seja um trabalho relativamente regulamentado, relativamente formalizado - tem todo o capítulo das lutas sociais do trabalho exigindo a regularização, a formalização do trabalho, os direitos do trabalhador, a redução e a regulamentação da jornada de trabalho, o descanso semanal, tudo aquilo que as lutas operárias dos séculos XIX e XX (levante de 1848, Comuna de Paris, 1848, as revoluções socialistas do século XX) que aqui não podemos desenvolver. Apesar dessa regulamentação do trabalho, tratava-se de um trabalho maquinal, parcelar, fragmentado, fetichizado, coisificado e alienado. Este é o trabalho que o Chaplin genialmente caricatura.

Lukács escreveu em História e Consciência de Classe a fragmentação taylorista do trabalho penetrava até a "alma do trabalhador", dando os contornos mais gerais do complexo da coisificação e do estranhamento do trabalho, numa complexa articulação entre o mundo da materialidade e o mundo da subjetividade operária. Gramsci, como eu já mencionei acima, desenvolveu é a idéia do homem integral para o capital: controle até da sexualidade dos trabalhadores na fábrica moderna e a projeção dessa forma da dominação que nasce na fábrica e se amplia para sociedade. A Classe Operária vai ao Paraíso do Elio Petri fotografa muito bem isso no contexto do "outono quente" das lutas de classe na Itália dos anos 1969-70.

Não é por acaso que o Taylor dizia que os trabalhadores seriam uma espécie de "gorilas amestrados". Ou seja, operava uma certa desconsideração do intelecto do trabalho. O trabalhador é um animal, tem que ser dócil. Mas o trabalho taylorista-fordista, o trabalho capitalista da era da indústria do automóvel e dos seus prolongamentos ao longo de todo o século XX, era um trabalho marcado por uma alienação/estranhamento, por esse caráter parcelar, fragmentado, da indústria seriada, da produção em série. No binômio taylorismo/fordismo, a concepção e a elaboração são responsabilidade da gerência científica; a execução (manual) é responsabilidade dos trabalhadores. Marx dizia no século XIX (e isso se manteve no taylorismo), que a fábrica só pode funcionar com um exército de feitores controlando o trabalho, num despotismo fabril acentuado. Por isso o século XX se caracterizou como uma variante da sociedade do trabalho alienado, típico da era taylorista-fordista.

Mas a partir do final do século XX, especialmente a partir dos anos 1970/80 o mundo capitalista sofre mutações no seu interior. É evidente que o mundo da empresa flexível, como diz o capital, ou o mundo da acumulação liofilizada, o mundo da empresa capitalista não altera a forma de ser do capital, mas alteram, em muitos pontos, os mecanismos do padrão de acumulação do capital. E isso tem conseqüências na própria subjetividade, nas distintas manifestações do fenômeno da alienação e do estranhamento. Até 
porque a alienação e o estranhamento não podem jamais ser reduzidos ao mundo da economia. E na era da acumulaşão flexivel o trabalho se torna aparentemente - no sentido marxiano do termo, onde a aparência é parte da essência, mas quando a aparência é concebida em si mesmo, isolada, como sinônimo da essência, ela se torna falsidade.

Quem conhece uma fábrica, como ela era na era taylorista-fordista e vê uma fábrica hoje percebe que a diferença é visível no seu desenho espacial, de trabalho, de organização técnica e de controle do trabalho. Não tem mais as divisórias. Não tem mais o restaurante do "peão" e o restaurante da gerência. É aparentemente mais "participativa", aparentemente mais envolvente e aparentemente menos despótica.

Em contrapartida, o trabalho é mais desregulamentado, mais informalizado, mais precarizado, mais intensificado, mais "polivalente", mais "multifuncional", seguindo critérios de "metas", "competências", etc. É feito em equipe, onde a competição é terrível entre os trabalhadores e as trabalhadoras. O toyotismo só pode viver - e as formas distintas de empresa flexivel - com base no envolvimento, na expropriação do intelecto do trabalho. Então certamente o Taiichi Ohno (engenheiro fundador desse receituário) não concordaria com a máxima do Taylor de que o trabalhador é só um "gorila amestrado".

Isso configura uma alienação que é mais interiorizada. $\mathrm{O}$ trabalhador e a trabalhadora têm que se envolver. Ele não é mais trabalhador, é definido como "colaborador ou colaboradora", "consultor". A alienação/estranhamento é aparentemente - atenção! - aparentemente menos despótico, mas intensamente mais interiorizado. Porque é assim que o toyotismo pode envolver. E para que haja o envolvimento, tem que fazer algumas concessões, senão não há base para o envolvimento.

$\mathrm{Na}$ fábrica taylorista e fordista tradicional o despotismo é explicito. Da planta flexível, eu usei no livro Adeus ao Trabalbo? a seguinte fórmula: as empresas querem converter os trabalhadores em déspotas de si mesmos!

Estamos longe da apologética do capital, ao afirmar que o mundo produtivo eliminou a alienação/estranhamento, tese que não se sustenta. Nós temos, então, que compreender estas formas mais interiorizadas e mais complexificadas da alienação e do estranhamento. É o que venho procurando desenvolver em minhas pesquisas.

E isto nos leva, finalmente, a desenvolver a terceira nota: qual o projeto da educação para o capital?

\section{Terceira nota: Os modos distintos da educação para o capital.}

Infelizmente, o tempo nos obriga a resumir de modo breve: qual foi a educação do capital? A educação taylorista-fordista é uma educação formal, parcelar, hierarquizada. Quem elabora? A gerência científica. Toda a concepção é da administração, os que pensam, elaboram; e a execução é responsabilidade dos trabalhadores. O Homo sapiens e o Homo faber. Esta é toda a concepção da gerência científica tayloriana. Depois com o Fordismo, com Fayol, com Elton Mayon, etc, todas as mudanças nas 
escolas da administração tomam como ponto de partida esta disjuntiva. E o que é, então, qualificar-se para o mercado de trabalho de tipo parcelar, especializado: ela é responsabilidade das ciências também especializadas, as ciências exatas, as biomédicas, as humanas. Por isso é um projeto de educação, no fundo, pois não há como desenvolve-los aqui, voltado para o exercício do trabalho unilateralizado, seja nas escolas técnicas profissionalizantes, seja nas escolas superiores: as médicas, as humanas, as engenharias. É o que estou denominando como a pragmática da especialização fragmentada. É a escola da pragmática da especialização fragmentada. A educação moldada por uma pragmática tecno-científica, qualificadora do mercado de trabalho gerencial, profissional, coisificado.

Deixo de lado aqui, um problema complicado e rico, que são as contradições da escola, especialmente da escola pública na era do welfare state e mesmo nas sociedades capitalistas como a nossa, onde a escola pública também é suscetível das contradições que estão no seio da sociedade. A escola não é um mero epifenômeno da economia. Tem traços e elementos das contradições, que eu talvez ao final, retomando Gramsci, possa indicar um pouco. Mas aqui estou indicando, inicialmente, os contornos mais gerais do projeto do capital para a educação no século XX, na era tayloriano/fordista. Agora quero indicar alguns elementos que estão presentes na era da acumulação flexivel, volátil, financeirizada e liofilizada.

Sabemos que a noção de tempo (vital para Marx) mudou. Uma categoria chave em O Capital é a noção de tempo - e o Marx tem várias passagens dessa obra em que ele diz que o tempo é a medida da sociedade. Pois bem, o tempo hoje é outro. O espaço é outro. A produção também é outra, como vimos procurando mostrar em vários de nossos textos. A educação, dizem os ideólogos do capital, deve ser outra. E qual deve ser a educação na era da acumulação financeirizada e flexibilizada do mundo (destrutivo) do capital dos nossos dias? Deve ser uma educação, "ágil”, "flexível" e "enxuta", como são as empresas capitalistas hoje. Aliás, não é por acaso que as grandes corporações inventaram a chamada "Universidade Corporativa". Se as Universidades públicas ainda discutem uma sociedade alternativa, outro modo de produção e de vida, as formas de reinvenção do socialismo, eles criam a Universidade Corporativa. Eles querem forjar seus quadros lá dentro das empresas. Aliás, não pode haver maior contradição em termos: uma universidade corporativa: universidade lembra universalidade; corporação lembra restrição, interesses restritos e específicos.

Qual a nova pragmática da educação do capital em nossos dias: no ensino superior, expandemse os cursos flexíveis! Núcleo básico para curto, rápido, no menor tempo de escolarização. Ensino não presencial. A real substância do ensino não conta.

Você fala para alguns milhões e não tem mais o contato presencial. É na verdade uma pragmática flexível para uma sociedade liofilizada (Parêntese: como liofilização não é um termo das ciências sociais, uma explicação rápida. Na química, liofilizar significa, em um processo de temperatura baixa, secar, reduzir as substâncias vivas. O leite em pó é um leite liofilizado. Então você seca a substância viva).

O que é, então, a educação liofilizada da empresa liofilizada? É uma educação enxuta para uma empresa com cada vez menos trabalhadores e trabalhadoras. 
Esta me parece ser a educação do modo de produção capitalista dos nossos dias. A pragmática da especialização, na variante taylorista-fordista, e a pragmática da liofilização e da flexibilização, na era da acumulação flexível.

\section{Um excerto breve e necessário: a educação para além do capital.}

O que seria, então, uma educação numa sociedade para além do capital, livre das engrenagens e dos constrangimentos da dominação do capital. Numa sociedade, como diria Marx, emancipada, estruturada a partir da associação livre, dos indivíduos livremente associados, dos trabalhadores livremente associados. Que exerceriam seu trabalho segundo o tempo disponivel voltado para a produção de bens socialmente úteis.

Haverá algo mais vital hoje do que pensar num mundo onde a produção seja o fazer, a criação de bens materiais e simbólicos para a humanidade, contra a dominante produção destrutiva? Isto nos obriga a refletir em profundidade acerca da questão ambiental, da questão do trabalho, da produção destrutiva, do tempo de vida e do tempo de trabalho, dentre tantos outros temas que são fundamentais hoje.

Então, dado esse princípio societal concebido a partir da busca da emancipação humana, Gramsci indicou pistas decisivas para se pensar a educação fora dos marcos da separação entre trabalho intelectual e trabalho manual, entre homo sapiens e homo faber. Isto porque toda a educação do capital se assenta nessa disjuntiva e nessa divisão. O que nos leva a desenhar a necessidade de uma educação humanista e efetivamente omnilateral. Não unilateral. Seja a unilateralidade taylorista/fordista - por isso eu a denominei como a pragmática da especialização fragmentada - seja a unilateralidade da liofilização flexivel, flexível na adequação uma aos imperativos do mercado, reduzindo-nos, como dizia o Marx n'O Capital, a uma personificação do capital.

A educação e o trabalho na sociedade emancipada devem retomar o trabalho como atividade vital, resgatando o sentido do trabalho como atividade vital. E, quanto menor for o tempo destinado ao trabalho, maior será o tempo verdadeiramente livre fora do trabalbo e realmente dotado e sentido, dando concretude a plena dimensão omnilateral.

Eu termino esta exposição com uma breve referência ao Gramsci. Em texto seminal que trata do debate travado na Itália nos inícios do século XX sobre a educação - com o título Homens e máquinas ele assevera:

O proletariado precisa de uma escola desinteressada. Uma escola na qual seja dada à criança a possibilidade de ter uma formação. De tornar-se homem. De adquirir aqueles critérios gerais que servem para o desenvolvimento do caráter. Em suma, uma escola humanista. Tal como a entendiam os antigos, e mais recentemente, os homens do renascimento. Uma escola que não hipoteque o futuro da criança, e não constrinja sua vontade, sua inteligência, sua consciência em formação, a mover-se por um caminho cuja meta seja prefixada.

E acrescenta: 
Uma escola de liberdade, e de livre iniciativa, não uma escola de escravidão, e de orientação mecânica. Também os filhos do proletariado devem ter diante de si todas as possibilidades. Todos os terrenos livres para poder realizar sua própria individualidade, do melhor modo possível. E por isso, do modo mais produtivo para eles mesmo e para a coletividade.

"Produtividade" e "livre iniciativa", naturalmente, encontram aqui outra conotação. E conclui:

A escola profissional não deve se tornar uma incubadora de pequenos monstros aridamente instruídos para um ofício, sem idéias gerais, sem cultura geral, sem alma, mas só com o olho certeiro e a mão firme.

E com isto eu termino esta apresentação. Como é que se poderia pensar uma sociedade onde um outro modo de produção e um outro modo de vida pudesse conviver com uma outra escola? Obrigado.

\section{Notas:}

${ }^{1}$ Fala proferida durante o debate promovido pelos Grupos MHTLE, HISTEDBR e LEPEL, com a finalidade de produzir a primeira seção do primeiro número da Revista Germinal: Marxismo e educação em debate, com o tema o Modo de produção e educação. A transcrição dessa apresentação foi realizada pelos estudantes de graduação Vanessa da Silva Guilherme e Andrei Marconi e revisada por Elza Peixoto e pelo autor.

${ }^{2}$ Bolsista de Produtividade em Pesquisa 1B. Orientador de Doutorado. Doutorado em Ciências Sociais pela Universidade de São Paulo, Brasil (1986). Pós-Doutorado pela University of Sussex, Inglaterra (1998). Livre Docência pela Universidade Estadual de Campinas, Brasil (1994). PROFESSOR TITULAR da Universidade Estadual de Campinas , Brasil. Email: rantunes@unicamp.br 